\title{
First evidence of underwater sounds emitted by the living fossils Lepidurus lubbocki and Triops cancriformis (Branchiopoda: Notostraca)
}

\author{
G. Buscaino ${ }^{1, *}$, M. Ceraulo ${ }^{1}$, D. E. Canale ${ }^{1}$, E. Papale ${ }^{1,2}$, F. Marrone ${ }^{3}$ \\ ${ }^{1}$ BioacousticsLab, National Research Council, via del Mare, 6, 91021 Torretta Granitola, Italy \\ ${ }^{2}$ Department of Life Science and Systems Biology, University of Torino, 10124 Torino, Italy \\ ${ }^{3}$ Department of Biological, Chemical and Pharmaceutical Sciences and Technologies (STEBICEF), University of Palermo, \\ via Archirafi 18, 90123 Palermo, Italy
}

\begin{abstract}
Sound is the most effective means of communication in marine and freshwater ecosystems. However, no data about acoustic emissions from non-malacostracan crustaceans are currently available, so their ability to produce sounds is unknown. For the first time, this study investigated the sound produced by 2 tadpole shrimp species, Triops cancriformis and Lepidurus lubbocki. L. lubbocki individuals were collected from a natural temporary pond in Sicily (Italy), whereas T. cancriformis individuals were obtained from eggs contained in sediment from a rock pool in Sardinia (Italy). In the laboratory, experimental tanks with the animals (one species at a time) were acoustically monitored. Both species produced high-frequency, wideband pulses distinguishable by their sound pressure level, which was higher in L. lubbocki $(146 \mathrm{~dB})$ than in $T$. cancriformis $(130 \mathrm{~dB})$, and by their first and second peak frequencies, which were higher in L. lubbocki (65 and $86 \mathrm{kHz}$ ) than in T. cancriformis (63 and $71 \mathrm{kHz}$ ). The energy distributions in the power density spectra showed different shapes, as revealed by the $3 \mathrm{~dB}$ bandwidth and centre frequency. The pulse durations were 88 and $97 \mu \mathrm{s}$ in L. lubbocki and T. cancriformis, respectively. $L$. lubbocki presented a higher emission rate than $T$. cancriformis and a marked circadian pattern, with a higher abundance of sounds during the night. This study reports the first evidence of sound emissions from non-malacostracan crustaceans and reveals the high potential of passive acoustic monitoring to detect the presence, abundance, and life cycle of these elusive keystone species of temporary water bodies.
\end{abstract}

KEY WORDS: Notostraca $\cdot$ Sounds $\cdot$ Passive acoustic monitoring $\cdot$ Temporal pattern

\section{INTRODUCTION}

In the animal world, communication between individuals is generally carried out through olfactive, tactile, electrical, visual, and hearing/sound perception mechanisms (Halliday \& Slater 1983, Ferrara et al. 2014). The first 3 mechanisms require short distances and thus are not efficient for communication at long distances (Norris \& Evans 1988); in contrast, the last 2 mechanisms are defined as 'teleportive'

\footnotetext{
${ }^{*}$ Corresponding author: giuseppa.buscaino@cnr.it
}

since they involve information exchange over large distances without direct contact (Norris \& Evans 1988). Among these mechanisms, acoustic communication has a certain number of advantages related to species selectiveness, light-condition independence, and distance transmission capabilities (Norris \& Evans 1988, Rosenthal \& Ryan 2000).

In an aquatic medium, the velocity of sound propagation is 4.3 times faster than that in the air. This makes acoustic signal exchange very efficient for

๑) The authors 2021. Open Access under Creative Commons by Attribution Licence. Use, distribution and reproduction are unrestricted. Authors and original publication must be credited. 
many marine and freshwater vertebrate and invertebrate species, which use acoustic signals for several purposes: mating, courtship, and partner selection (Lugli et al. 1995, Amorim \& Vasconcelos 2008, Buscaino et al. 2015a, Sal Moyano et al. 2019), prey and/ or predator location (Buscaino et al. 2011a,b, Salgado Costa et al. 2014), group cohesion and coordination (Janik \& Slater 1998, Buscaino et al. 2011b, Herzing 2015, van Oosterom et al. 2016), aggressive and agonistic intraspecific interactions (Ladich 1997, Simões et al. 2008, Buscaino et al. 2012), and spatial orientation (Tolimieri et al. 2000, Jeffs et al. 2003, Montgomery et al. 2006). All these behaviours are essential for individual survival, emphasizing the role of sound in the aquatic environment, especially for species inhabiting extreme habitats where light does not reach due to depth or turbidity, making other communication systems inefficient.

Temporary lentic water bodies, such as temporary ponds, are recognized as extreme habitats and key freshwater ecosystems for biodiversity conservation (Bagella et al. 2016) and are protected as priority habitats by the European Habitats Directive. These water bodies are usually small and shallow and are characterized by an alternation of flooded and dry phases, leading to the development of highly specialized plant and animal communities (Pérez-Bilbao et al. 2015). The organisms inhabiting these habitats develop morphological adaptations, life cycles, and dispersal mechanisms that allow them to survive through dry seasons and to quickly exploit flooded phases (Williams 1997, Incagnone et al. 2015). Among these organisms, some aquatic invertebrates are strictly linked to temporary ponds since they require a dry phase to complete their life cycle. The species from the branchiopod order Notostraca (tadpole shrimp) are considered typical of these habitats, of which these species are often considered 'flagship taxa' (Brendonck et al. 2008). Order Notostraca is an ancient group of branchiopod crustaceans that has existed since the Late Devonian and is a prime example of morphological and ecological stasis (Korn et al. 2013, Gueriau et al. 2016). The order Notostraca includes a single family and 2 extant genera, Triops and Lepidurus, which are distributed worldwide (Brendonck et al. 2008). With the only exception of L. arcticus, which is able to colonize permanent, fish-inhabited lakes at higher latitudes (Jeppesen et al. 2001), all notostracan species are monovoltine and strictly linked to temporary inland water bodies, where they survive drought or frost thanks to the production of resting eggs. These eggs are also passively dispersed by biological and physical vectors, thus allowing the colonization of new water bodies and the existence of interpopulation gene flow (Incagnone et al. 2015). As large-bodied omnivorous scavengers and opportunistic predators, notostracans are keystone species and ecosystem engineers in inhabited water bodies (see Waterkeyn et al. 2016 and references therein), where they are often preyed upon by vertebrates, mostly birds. Due to their key role in aquatic habitats, the occurrence of notostracans also has a renowned impact on human activities, and different notostracan species are considered either pests in some cultures (e.g. Tindall \& Fothergill 2012) or effective agents for the biological control of noxious taxa (e.g. Fry et al. 1994, Takahashi 1994). Multiple alternative reproductive modalities are known for tadpole shrimp, with even conspecific populations ranging from parthenogenesis to androdioecy and gonochorism (e.g. Longhurst 1955, Zaffagnini \& Trentini 1980, Sassaman 1991, Zierold et al. 2007, Velonà et al. 2009). When males are present, no clear sexual dimorphism can be observed apart from the morphology of the $11^{\text {th }}$ trunk limbs, which are transformed into egg-bearing oostegopods in females (Longhurst 1955). With sporadic exceptions (e.g. Thiéry 1991), different notostracan species generally do not share the same pool, and it was demonstrated that temperature is an important environmental factor controlling their distribution and hatching process (Fryer 1988, Williams \& Busby 1991, Kuller \& Gasith 1996, Pasquali et al. 2019).

Although these primeval species are very important from an evolutionary perspective, little information is currently available about their behaviours and communication systems. Pasquali (2015) and Pasquali et al. (2017) showed the presence of locomotor activity rhythms in L. arcticus, a species adapted to polar environments, but to the best of our knowledge, no information is available for notostracan species at lower latitudes.

Moreover, to date, no information about the acoustic communication of or the production of underwater sounds by non-malacostracan crustaceans is available, whereas a rich body of literature exists with respect to both freshwater (e.g. Sandeman \& Wilkens 1982, Favaro et al. 2011, Buscaino et al. 2012, Filiciotto et al. 2019) and marine (e.g. Popper et al. 2001, Radford et al. 2008, Buscaino et al. 2011a, 2015a, Bohnenstiehl et al. 2016, Coquereau et al. 2016) decapods. Non-malacostracan crustaceans are thus considered unable to produce underwater sounds. To determine whether this assumption is true, 2 temporary inland water body 'flagship species', the noto- 
stracans L. lubbocki and Triops cancriformis, were tested for the production of acoustic emissions. In particular, we evaluated (1) the presence and number of acoustic signals emitted by $L$. lubbocki and $T$. cancriformis in a controlled environment; (2) the temporal and spectral acoustic characteristics of the emitted signals and possible inter-species differences; and (3) possible difference in the abundance of produced sound between day and night.

\section{MATERIALS AND METHODS}

\subsection{Animal collection and laboratory maintenance}

Triops cancriformis and Lepidurus lubbocki (i.e. 2 of the 4 notostracan species currently reported to occur in Italy; Ruffo 2005, Mathers et al. 2013) were included in the present study. Sediment samples containing the resting eggs of a male-less T. cancriformis population were collected from a rock pool close to Orosei, northeastern Sardinia (Fig. 1; site 'P6' in Stella et al. 1972). Subsamples of the collected sediment were placed in cultures in individual aquaria following Sars' method as described in Marrone et al. (2019). Upon hatching, T. cancriformis were fed a mixture of commercial fish fry food (sera Micron) and ground fish flakes (sera Vipan) ad libitum. At $24 \mathrm{~d}$ post-hatch, when individuals reached a carapace length of approximately $12 \mathrm{~mm}$, they were removed from the breeding aquaria and moved to experimental tanks which were filled with micro-filtered water of the same chemical and physical characteristics as that in the breeding aquaria.

L. lubbocki specimens were collected on 30 November 2018 in Pantani di Anguillara (Troia et al. 2016) with a $1 \mathrm{~mm}$ mesh hand net (Fig. 1). The collected individuals had a carapace length of approximately $14 \mathrm{~mm}$ and a balanced sex ratio. They were brought to the laboratory in micro-filtered pond water and moved to experimental tanks.

Both T. cancriformis and L. lubbocki individuals in the experimental tanks were exposed to a natural photoperiod, fed once every $2 \mathrm{~d}$ with the food mixture described above, and kept in those tanks until the end of the measurements.

\subsection{Acoustic recordings}

Acoustic data were collected in the laboratory of the Department of Biological, Chemical and Pharmaceutical Sciences and Technologies (STEBICEF) at the University of Palermo, Italy. The recording system was composed of a calibrated hydrophone (type 8104 , Bruel \& Kjer) with a sensitivity of $-205.6 \mathrm{~dB}$ re $1 \mathrm{~V} / 1 \mu \mathrm{Pa} \pm 4.0 \mathrm{~dB}$ in the $0.1 \mathrm{~Hz}$ to $80 \mathrm{kHz}$ frequency band $(+4 \mathrm{~dB}$ and $-12 \mathrm{~dB}$ in the frequency range of $0.1 \mathrm{~Hz}$ to $120 \mathrm{kHz}$ ) connected to a digital acquisition card (USGH416HB, Avisoft Bioacoustics, set at a $40 \mathrm{~dB}$ gain) managed by dedicated Avisoft Recorder USGH software (Avisoft Bioacoustics). The signals were acquired at 300000 samples $\mathrm{s}^{-1}$ at 16 bit resolution.

To avoid attributing external environmental noise or internal acquisition system noise to the species under investigation, a control tank without any animals was monitored contemporaneously with the experimental tank (Fig. 2). The 2 tanks were equipped with 2 identical hydrophones connected to 2 channels of the same digital card (Fig. 2).

Following the working protocol for sound recordings in small tanks described by Akamatsu et al. (2002), we consid ered the minimum dimensions of the tanks $(28 \times 20 \times 10 \mathrm{~cm})$ and compared them with the distance that sound can travel during the pulse duration of animal sound. For our study, the median pulse durations were 88 and $97 \mu$ s (see Table 1), which correspond to travel distances of 13 and $15 \mathrm{~cm}$, respectively. Because the minimum dimensions of the tanks were not much higher than the distance the sound could travel during its duration, the original sound was potentially prolonged when the direct and reflected waves could not be separated. Otherwise, we were able to characterize the peak frequencies of the species considered in this study because these peaks were much higher (see Table 1) than the minimum resonant frequency of the experimental tank (8.4 kHz).

\subsection{Experimental test}

We continuously acoustically monitored L. lubbocki for $187 \mathrm{~h}$ from 13 to 21 December 2018 and $T$. cancriformis for $538 \mathrm{~h}$ from 10 March to 1 April 2020. During the recording periods, each experimental tank was positioned near the laboratory window and exposed exclusively to the natural photoperiod. The experimental tank used for L. lubbocki contained 10 specimens, and the tank used for T. cancriformis contained 5 specimens. The tanks were visually monitored twice a day, and dead animals were promptly replaced with new animals. The total numbers of animals used for this study were 14 for L. lubbocki and 10 for T. cancriformis. 

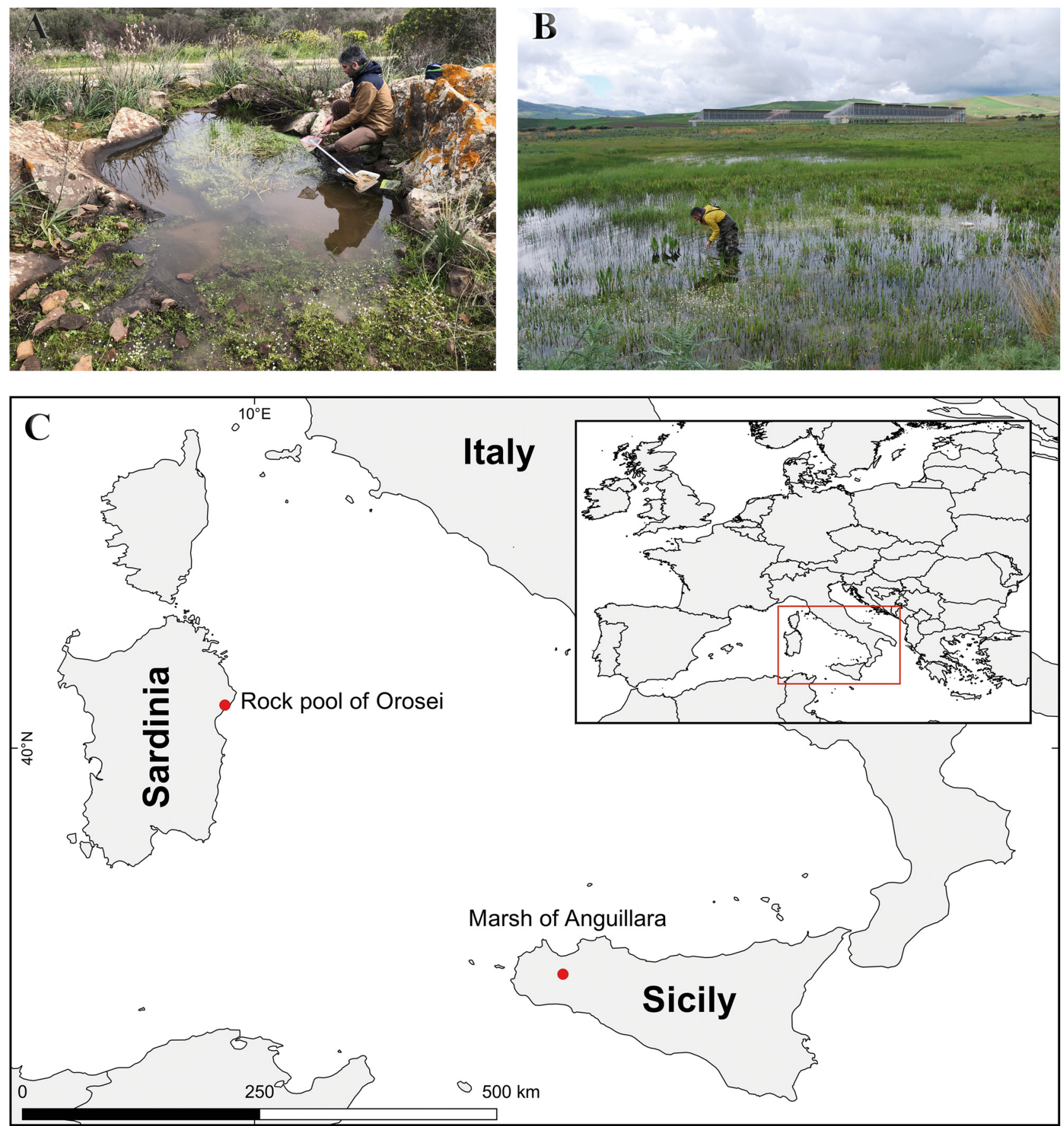

Fig. 1. (A) Orosei and (B) Anguillara sampling sites for Lepidurus lubbocki and Triops cancriformis and (C) their location on Sardinia and Sicily

\subsection{Acoustic analysis}

To exclude signals due to noise (either environmental or internal from the acoustic acquisition system), the 2 channel wave files were visualized using an oscillogram and a spectrogram (Avisoft Saslab), and we excluded those files in which the acoustic signals were present in both the experimental and the control tanks.

Then, a program was developed in MATLAB (version 2019b) to count and characterize the sounds possibly produced by L. lubbocki and T. cancriformis. The code first applied a high-pass filter (cut-off frequency $3 \mathrm{kHz}$, order 50) and then the 'Teager Kaiser' 


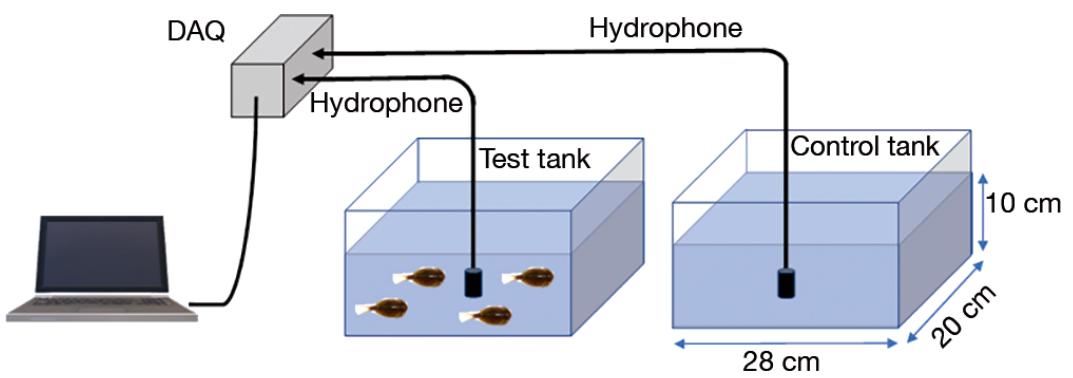

Fig. 2. Schematic view of the experimental setup (not to scale). DAQ: digital acquisition system

operator (Kaiser 1990). This operator has already been applied with success to detect impulsive signals from freshwater and marine animals (Buscaino et al. 2015b, 2016, Papale et al. 2020). Because the signals of our species are characterized by a high frequency and an increase in instantaneous energy (Fig. 3), this operator has an advantage over methods that look only at an increase in signal energy or amplitude.

An empirical threshold, which was the same for all analyses, was adopted to select all the pulses in the 'Teager Kaiser' signal that overcame this threshold. For each peak overcoming the threshold, we extracted a window around the peak from the $3 \mathrm{kHz}$ high-pass filtered waveform. The 'envelope' function was then applied to the window to calculate the pulse duration.
To evaluate the power spectral density (PSD), the MATLAB function 'pwelch' was applied to the window extracted from the waveformfiltered signal ranging between the onset and end of the pulse. The MATLAB code allows the operator to check and note if the signal should be counted, the duration should be corrected, and the PSD should be calculated.

On the waveform, we calculated the pulse duration, which was determined from the envelope of the waveform. The onset and termination of the pulse signal were defined as the points at which 10 and $5 \%$ of the peak value were reached, respectively (Fig. 3).

On the PSD, we calculated (1) the $1^{\text {st }}$ and $2^{\text {nd }}$ peak frequencies, i.e. the frequencies corresponding to the highest and second-highest amplitude values, respectively, determined from the PSD, (2) the $3 \mathrm{~dB}$ bandwidth (the frequency band between the lower and upper half-powers or $3 \mathrm{~dB}$ down from the maximum PSD), and (3) the centre frequency (the frequency that divides the energy in the spectrum into 2 equal parts so that the energy in the higher frequency portion of the spectrum is equal to the energy in the lower frequency portion of the spectrum).
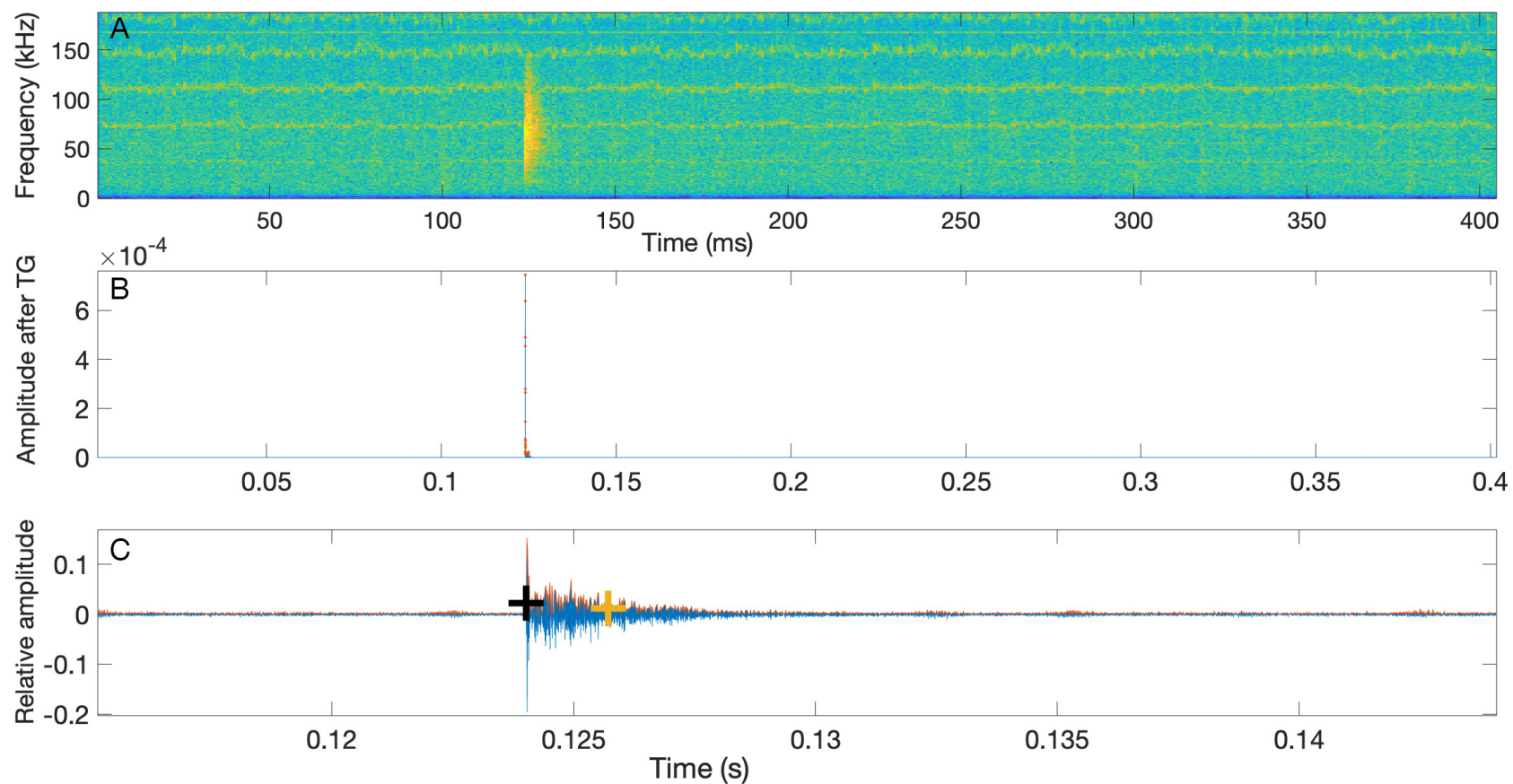

Fig. 3. Output figure of the MATLAB code used by the operator to check if the detection of the signal and signal duration were correctly attributed. (A) Spectrogram (Fast Fourier Transform length of 256, time segment overlap 50\%, with a Hamming window, sampling frequency of $300 \mathrm{kHz}$ ); (B) the waveform after applying the 'Teager Kaiser' (TK) operator; red points indicate overcoming the threshold; $(\mathrm{C})$ the waveform window selected around the detected signal showing the onset and end of the signal (black and yellow crosses, respectively) 


\subsection{Solar elevation}

We calculated the position of the sun in the sky by using the solar elevation angle with respect to the horizon line. Here, positive and negative angles indicate the presence or absence, respectively, of solar irradiation. The solar elevation angles were assessed using the MATLAB function 'SolarAzEl' (Koblick 2021) after inserting the geographical coordinates, metres above sea level (i.e. above the $0 \mathrm{~m}$ datum) and UTC time as the input.

\subsection{Statistical analysis}

To explore any differences in the abundance of produced sound between day and night, the MannWhitney $U$-test was applied after dividing the sounds produced by Lepidurus between those emitted during the night (negative solar elevation) and those produced during the day (positive solar elevation). Unfortunately, the data collected in the T. cancriformis experimental tank were not sufficient to be thoroughly analysed and were thus ignored (see below). Moreover, for all the acoustic parameters, the Mann-Whitney $U$-test was applied to assess differences between the 2 species. Statistica 8.0 software (StatSoft) was used for the statistical analysis.

\section{RESULTS}

\subsection{Presence and number of acoustic signals}

Signals were recorded from both species. Fig. 4 shows the number of sounds per day recorded for each species during monitoring. In particular, for Lepidurus lubbocki, we recorded the most sounds on $14,15,17$, and 18 December $(479,591,36.2$, and 463, respectively). During the first $24 \mathrm{~h}$ of monitoring, we registered only 1 sound that could be attributed to their manipulation, that is, changing their natural behaviour. However, on 16 December and during the last $3 \mathrm{~d}$ of monitoring, the number of sounds decreased. We observed a lower emis- sion rate for Triops cancriformis, with 2 peaks during 18 and 21 March (26 and 21 sounds, respectively), and no sounds were recorded on several days.

\subsection{Temporal and spectral acoustic characteristics of the signals and inter-species differences}

The sounds produced by both of these species are wideband, impulsive signals (Figs. 5 \& 6). The mean $( \pm \mathrm{SD})$ pulse duration for L. lubbocki was $110.2 \pm$ $85 \mu \mathrm{s}$, whereas that for T. cancriformis was $182.0 \pm$ $253 \mu \mathrm{s}$. Excluding the duration, all acoustic parameters revealed significant differences between the species (Tables 1 \& 2, Fig. 7). L. lubbocki produced a louder sound than $T$. cancriformis (Mann-Whitney $U$ test, $\mathrm{p}<0.0001$ ), with sound pressure levels (SPLs) of $145.5 \pm 8$ and $130.0 \pm 5 \mathrm{~dB}$ (peak, re $1 \mu \mathrm{Pa}$ ), respectively. Both the first and the second peak frequencies were significantly higher in L. lubbocki than in $T$. cancriformis. The central frequency of the PSD was higher for L. lubbocki than for T. cancriformis (Mann-
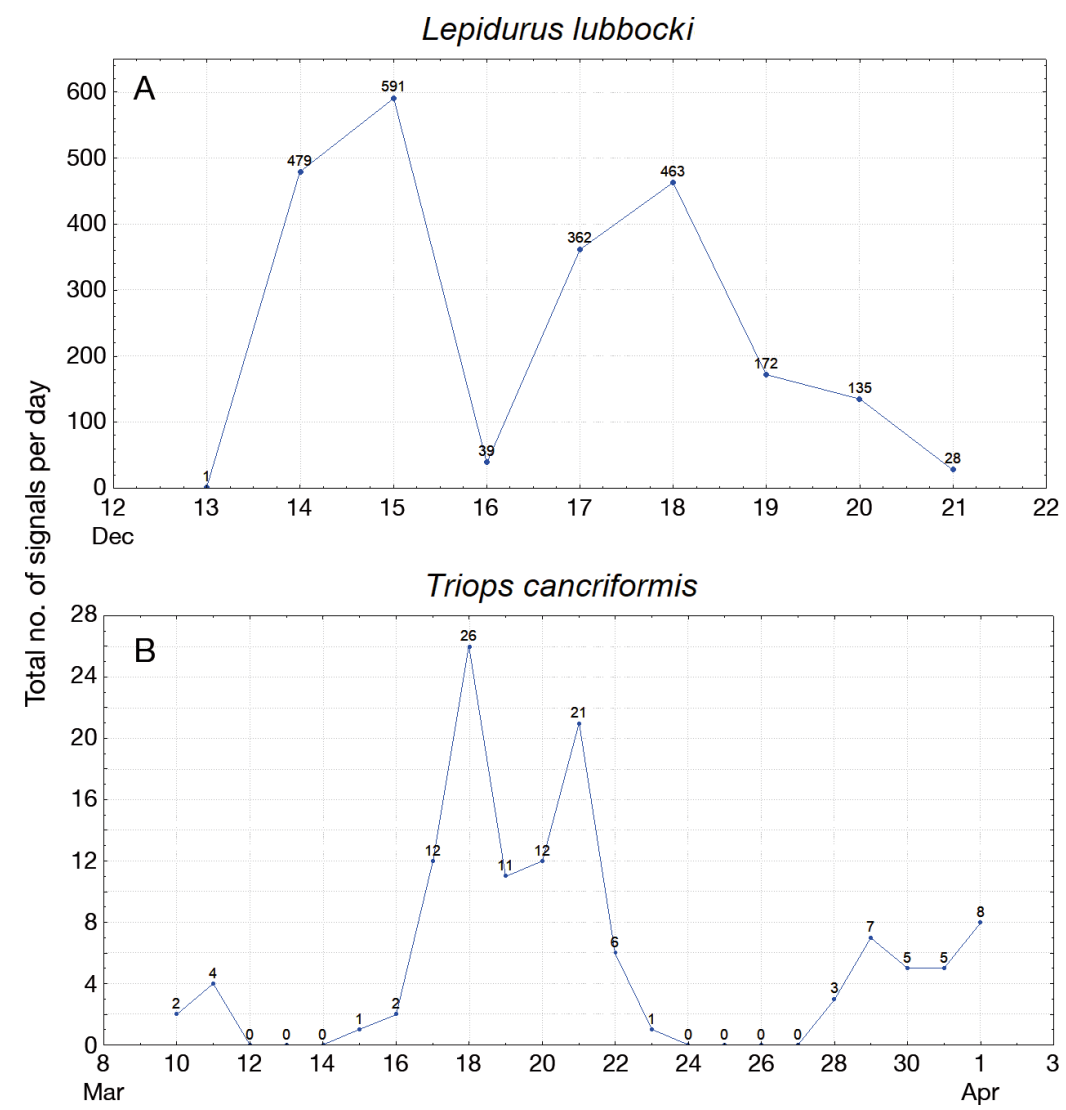

Fig. 4. Daily numbers of sounds recorded for (A) Lepidurus lubbocki in 2018 ( $\mathrm{n}=10$ specimens in the experimental tank) and (B) Triops cancriformis in $2020(\mathrm{n}=5$ specimens in the experimental tank) 

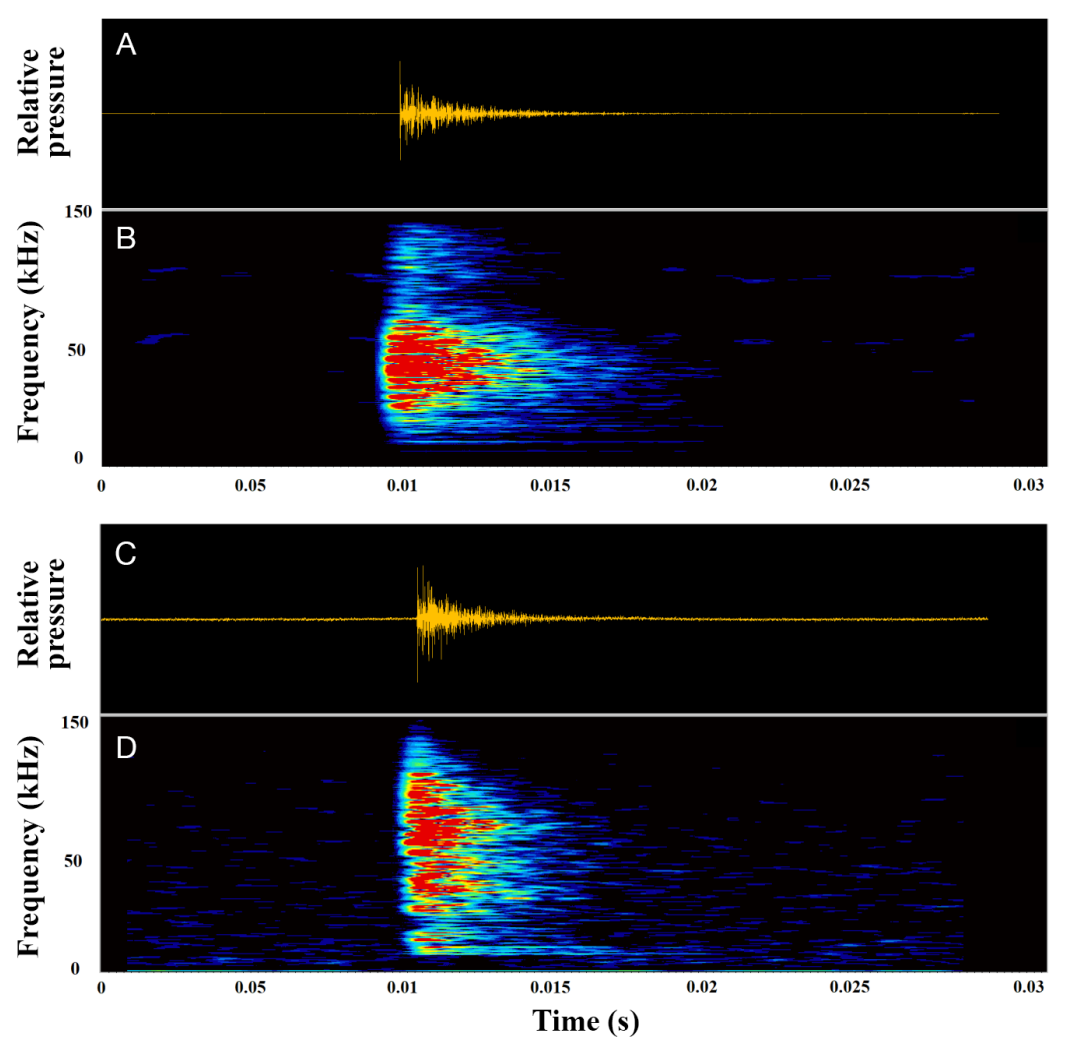

Fig. 5. (A,C) Oscillograms and (B,D) spectrograms (sampling frequency of $300000 \mathrm{~Hz}$, Fast Fourier Transform length of 512, Hamming window, resolution of $585 \mathrm{~Hz})$ for $(\mathrm{A}, \mathrm{B})$ Lepidurus lubbocki and $(\mathrm{C}, \mathrm{D})$ Triops cancriformis

Whitney $U$-test, $\mathrm{p}<0.0001)$. Otherwise, the $3 \mathrm{~dB}$ bandwidth was higher in $T$. cancriformis than in L. lubbocki (Mann-Whitney U-test, $\mathrm{p}<0.003$ ).

\subsection{Differences in the abundance of produced sound between day and night}

For both species, we observed strong variability in the emission patterns (Fig. 4). The most soniferous species was L. lubbocki. Fig. 8 shows the emission rate of this species during the day and the night. The difference between night (mean: $32 \pm 24$ signals) and day (17 \pm 11 signals) was significant (MannWhitney $U$-test: p < 0.02; sum rank [night] $=$ 2077, sum rank [day] = 698) .

T. cancriformis showed a very low sound emission rate compared with $L$. lubbocki (more than 10 times lower); these low numbers did not allow evidence of any pattern to be recognized for this species.

\section{DISCUSSION}

In this study, we report the first evidence for sound emission among branchiopod crustaceans, describing for the first time the underwater sounds emitted by the notostracans Lepidurus lubbocki and Triops cancriformis. No previous information about the emission of sound for the whole order Branchiopoda has been reported to date.

In marine crustaceans, sound production is associated with reproduction (Buscaino et al. 2015b, Sal Moyano et al. 2019), antipredator defense mechanisms (Patek et al. 2010, Buscaino et al. 2011b, Salgado Costa et al. 2014), feeding events (Coquereau et al. 2016), the stunning of prey (Versluis 2000), and intraspecific competition (Boon et al. 2009). To date, no data are available about the possible emission of sound by notostracans; however, we speculate that the emission of sound is associated with activity linked to feeding or inter-individual interactions. Further studies are needed to explore this issue.

The abundance of sounds emitted by L. lubbocki during the day showed high variability, whereas the

Table 1. Acoustic parameters and inter-species differences between tadpole shrimp Lepidurus lubbocki and Triops cancriformis. Med: median; $10^{\text {th }}: 10^{\text {th }}$ percentile; $90^{\text {th }}: 90^{\text {th }}$ percentile. SPL: sound pressure level ${ }^{\text {PSD: }}$ power spectral density

\begin{tabular}{|c|c|c|c|c|c|c|c|c|c|c|}
\hline \multirow{2}{*}{ Parameter } & \multicolumn{5}{|c|}{ Lepidurus lubbocki- } & \multirow{2}{*}{ No. } & \multicolumn{3}{|c|}{ Triops cancriformis } & \multirow[b]{2}{*}{$90^{\text {th }}$} \\
\hline & No. & Mean $( \pm \mathrm{SD})$ & Med & $10^{\text {th }}$ & $90^{\text {th }}$ & & Mean $( \pm \mathrm{SD})$ & Med & $10^{\text {th }}$ & \\
\hline Duration $(\mu s)$ & 346 & $110.2 \pm 85$ & 88.0 & 48.00 & 205.3 & 80 & $148.8 \pm 140$ & 96.7 & 37 & 313 \\
\hline SPL peak ( $\mathrm{dB}$ re $1 \mu \mathrm{Pa})$ & 232 & $145.5 \pm 8$ & 144.9 & 136.9 & 154.3 & 48 & $130.0 \pm 5$ & 129 & 123 & 138 \\
\hline $1^{\text {st }}$ peak frequency $(\mathrm{kHz})$ & 346 & $65.6 \pm 7.1$ & 64.9 & 57.7 & 74.6 & 82 & $62.7 \pm 18.2$ & 61.6 & 45.2 & 91.6 \\
\hline $2^{\text {nd }}$ peak frequency $(\mathrm{kHz})$ & 303 & $88.7 \pm 35.2$ & 85.5 & 43.78 & 142.7 & 70 & $70.8 \pm 32.8$ & 70.8 & 26.2 & 122.5 \\
\hline Bandwidth (3 dB) (Hz) & 50 & $334.6 \pm 176.9$ & 274.0 & 162.0 & 594.0 & 50 & $454.1 \pm 203.5$ & 423.5 & 220.0 & 790.5 \\
\hline PSD centre frequency $(\mathrm{kHz})$ & 346 & $66.6 \pm 6.5$ & 65.9 & 60.3 & 74.3 & 82 & $61.5 \pm 18$ & 60.3 & 40.9 & 87.7 \\
\hline
\end{tabular}




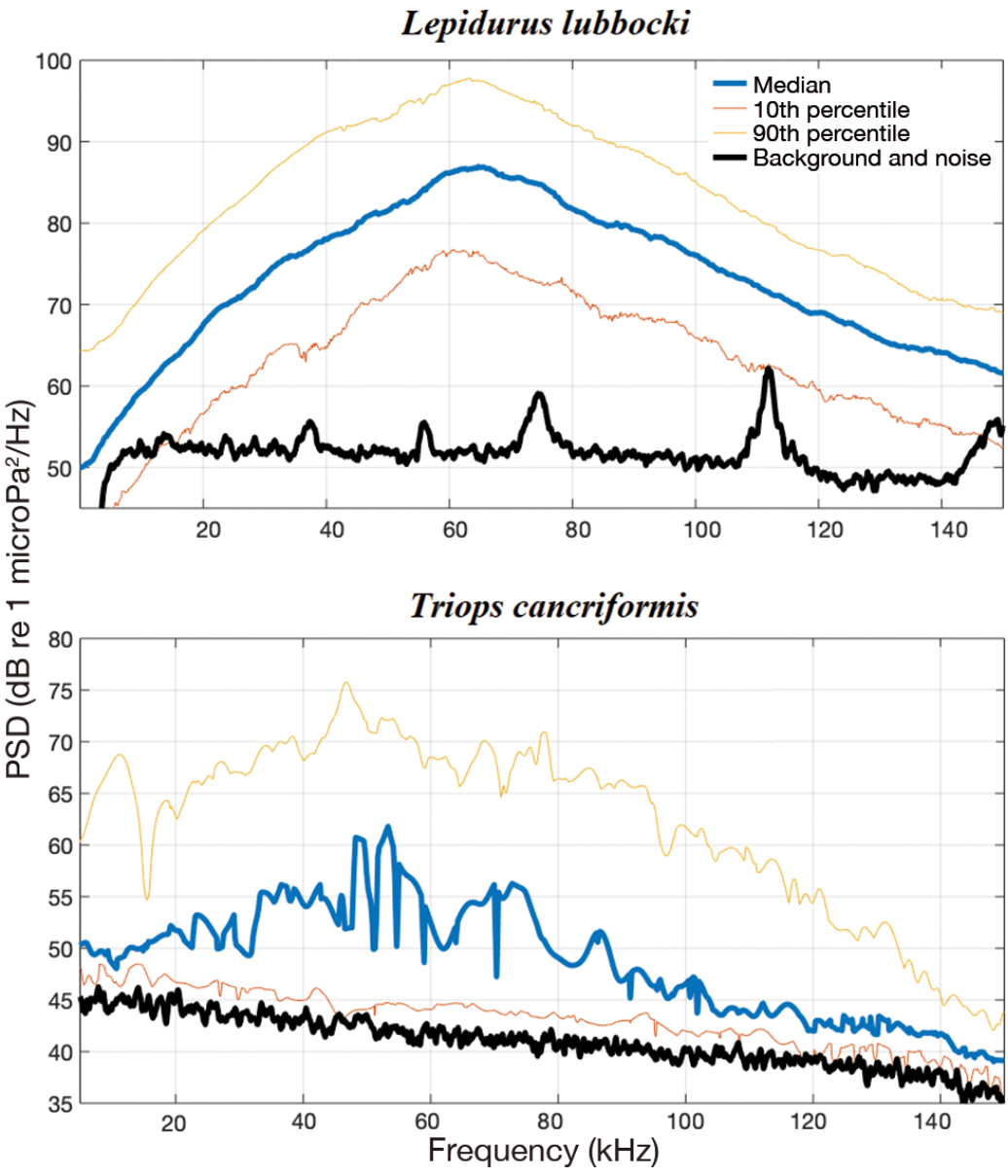

Fig. 6. Power spectral density (PSD; window size of 516, overlap 50\%) of sounds from Lepidurus lubbocki $(\mathrm{n}=346)$ with background noise in the tank $(\mathrm{n}=46)$ and from Triops cancriformis $(\mathrm{n}=74)$ with background noise in the $\operatorname{tank}(\mathrm{n}=20)$

abundance of sounds produced by T. cancriformis was much lower (see Fig. 4). The observed variability in the rate of sound emission, both between and within each species, is likely related to some intrinsic (i.e. the presence of an interacting conspecific animal, a maturity stage) or extrinsic (temperature, light, food availability) environmental factors that might boost sound production.

Focusing on the most acoustically active species, i.e. L. lubbocki, higher activity was clearly recorded during the night than during the day (Fig. 8). This finding is in accordance with what has been observed in some marine and freshwater crustacean species, which showed more intense nocturnal acoustic activity (Buscaino et al. 2012, 2015a, Kaplan et al. 2018). Intense nocturnal activity is generally related to a lower predator risk and the presence of low light conditions, which make acoustic communication more efficient than other communication systems. Even if notostracans have a well-developed visual system (Diersch et al. 1999), the limited visibility of their habitat due to turbid conditions, often caused by the notostracans themselves (Waterkeyn et al. 2016), could make the acoustic system the best means for interacting. In accordance with our results, Pasquali (2015) showed higher nocturnal activity of the Arctic notostracan species $L$. arcticus.

In $T$. cancriformis, no significant temporal pattern was evident from the collected data. Nevertheless, the low number of recorded signals may have hidden a temporal pattern, and further experiments are needed to define the absence or presence of circadian acoustic activity in this species.

Although the sounds emitted by the 2 species are both impulsive, the acoustic parameters were significantly different. L. lubbocki produced a louder sound than T. cancriformis (SPL peak $145.5 \pm 8$ and $130.0 \pm$

Table 2. Results of the Mann-Whitney $U$-test applied to demonstrate differences between the acoustic parameters corresponding to the 2 tadpole shrimp species Lepidurus lubbocki and Triops cancriformis. Bold numbers show significance ( $\mathrm{p} \leq 0.05$ ). SPL: sound pressure level; PSD: power spectral density

\begin{tabular}{|c|c|c|c|c|c|c|c|}
\hline Parameter & $\begin{array}{l}\text { Valid no. } \\
\text { Lepidurus } \\
\text { lubbocki }\end{array}$ & $\begin{array}{c}\text { Valid no. } \\
\text { Triops } \\
\text { Cancriformis }\end{array}$ & $\begin{array}{c}\text { Rank sum, } \\
\text { Lepidurus } \\
\text { lubbocki }\end{array}$ & $\begin{array}{c}\text { Rank sum, } \\
\text { Triops } \\
\text { cancriformis }\end{array}$ & $U$ & $Z$ & $\mathrm{p}$ \\
\hline Duration $(\mu \mathrm{s})$ & 346 & 82 & 72571.0 & 19235.0 & 12540.0 & -1.63 & 0.1022 \\
\hline SPL peak ( $\mathrm{dB}$ re $1 \mu \mathrm{Pa})$ & 232 & 48 & 37785.0 & 1555.0 & 379.0 & 10.16 & $<0.0001$ \\
\hline $1^{\text {st }}$ peak frequency $(\mathrm{kHz})$ & 346 & 82 & 77454.5 & 14351.5 & 10948.5 & 3.21 & 0.0013 \\
\hline $2^{\text {nd }}$ peak frequency $(\mathrm{kHz})$ & 303 & 70 & 59655.5 & 10095.5 & 7610.5 & 3.68 & 0.0002 \\
\hline $3 \mathrm{~dB}$ bandwidth $(\mathrm{Hz})$ & 50 & 50 & 1890.5 & 2862.5 & 762.5 & -2.97 & $<0.003$ \\
\hline PSD centre frequency $(\mathrm{kHz})$ & 346 & 82 & 78280.0 & 13526.0 & 10123.0 & 4.0 & $<0.0001$ \\
\hline
\end{tabular}



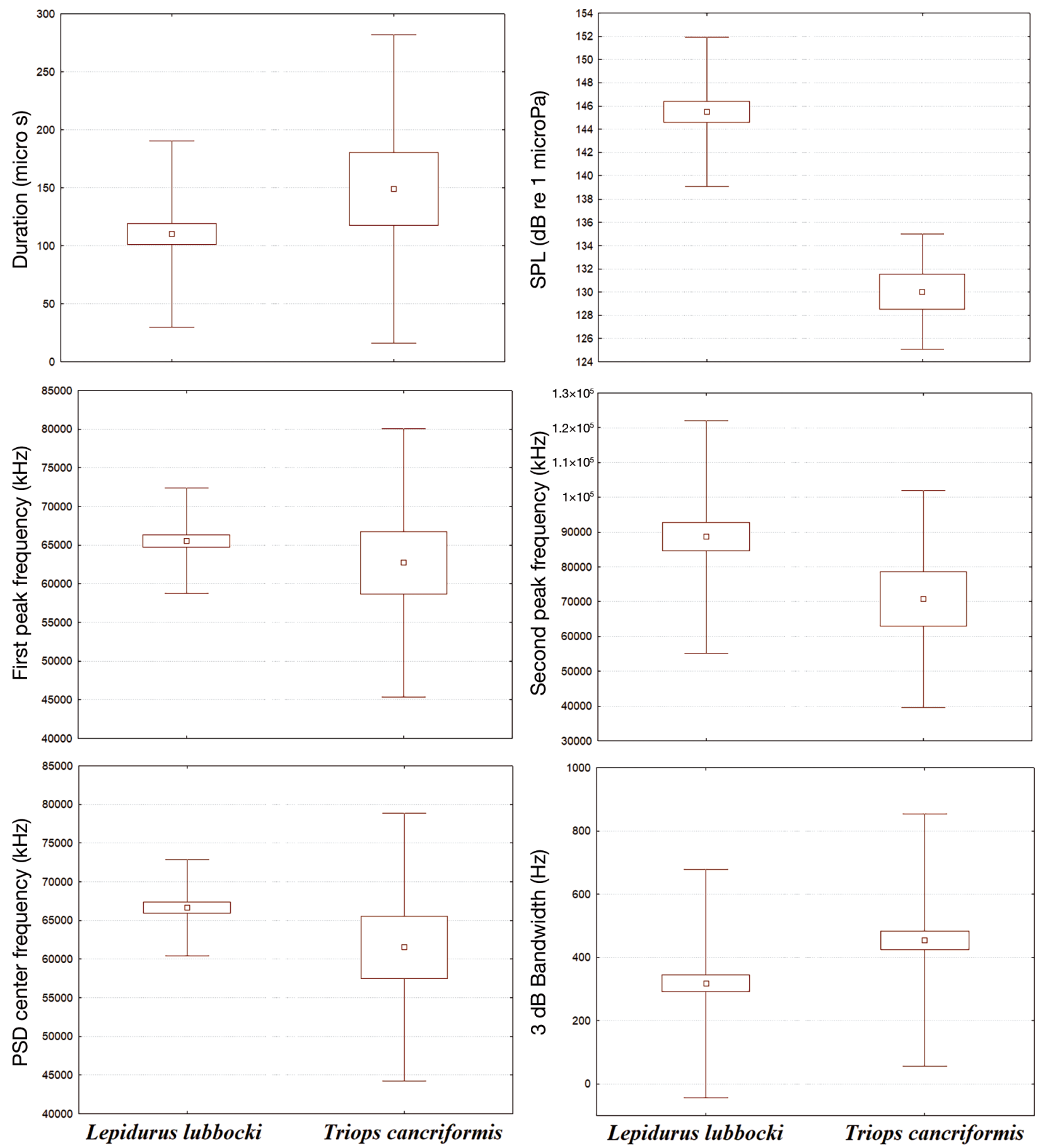

Fig. 7. Acoustic characteristics of sounds made by Lepidurus lubbocki and Triops cancriformis. PSD: power spectral density; SPL: sound pressure level. All parameters except duration were significantly different between the 2 species (Mann-Whitney $U$-test, $\mathrm{p}<0.002)$. Whiskers: $\pm 0.95 \times \mathrm{SD}$; boxes: $\pm 2 \times \mathrm{SE}$; symbols in the centre: mean

$5 \mathrm{~dB}$ re $1 \mu \mathrm{Pa}$, respectively) and presented a higher peak frequency, as also revealed by the PSD (see Fig. 7). The pulse duration could not be measured accurately in our tank because the original wave and its reflections from the tank walls could not always be separated. In the natural environment, where the dimensions of the inhabited water bodies are much larger than the distance that sound can travel during the pulse duration, this parameter would also be distinguishable between the species.

Based on the results of this study, we can conclude that these 2 species could be distinguishable in their 


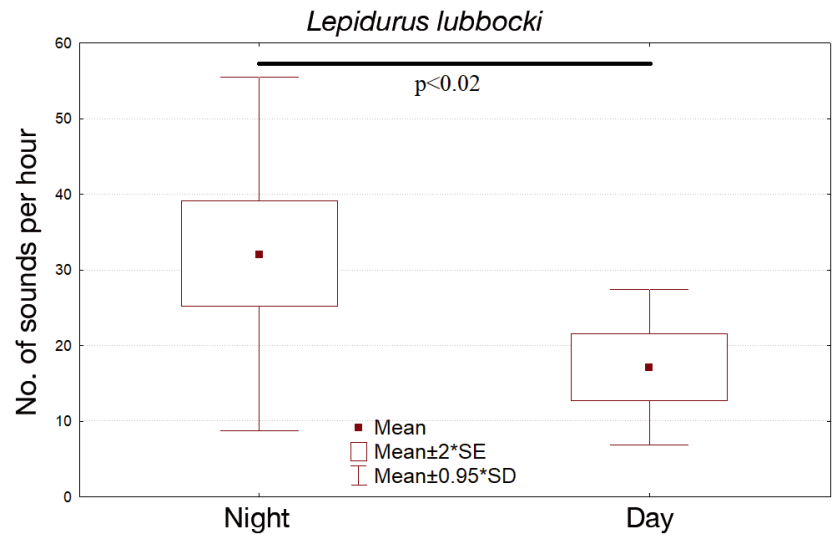

Fig. 8. Mean number of sounds per hour produced at night and day by Lepidurus lubbocki. Whiskers: $\pm 0.95 \times \mathrm{SD}_{i}$ boxes: $\pm 2 \times \mathrm{SE}$; symbols in the centre: mean

natural environment using a passive acoustic monitoring (PAM) approach. PAM is a useful and costeffective method to acquire information about an ecosystem at a fine temporal resolution (Buscaino et al. 2012, Desjonquères et al. 2015, Haver et al. 2017, Caruso et al. 2017, Ceraulo et al. 2018, 2020, Papale et al. 2020). The possible implementation of PAM for detecting the presence of active notostracans is a promising approach for carrying out a sound census of these elusive key species of temporary water bodies since adult notostracans are able to actively avoid nets during sampling activities, especially if their density is low; hence, their actual presence and distribution is often underrated. The implementation of PAM could thus be an effective and non-invasive method of revealing the actual presence of notostracans in a study area. In this context, characterizing the underwater sounds produced by other nonmalacostracan crustaceans inhabiting temporary water bodies is desirable so that a sound PAM protocol for the species inhabiting these biodiversity hotspots can be developed. We hope that this paper might pave the way for such an approach.

Acknowledgements. This research was carried out with the support of the CAIMAR Joint Laboratory Italy-Argentina (Joint Lab Project 2017-2019, funded by the Italian National Research Council).

\section{LITERATURE CITED}

Akamatsu T, Okumura T, Novarini N, Yan HY (2002) Empirical refinements applicable to the recording of fish sounds in small tanks. J Acoust Soc Am 112:3073-3082

Amorim MCP, Vasconcelos RO (2008) Variability in the mating calls of the Lusitanian toadfish Halobatrachus didactylus: cues for potential individual recognition. J Fish Biol 73:1267-1283

Bagella S, Gascón S, Filigheddu R, Cogoni A, Boix D (2016)
Mediterranean temporary ponds: new challenges from a neglected habitat. Hydrobiologia 782:1-10

* Bohnenstiehl DR, Lillis A, Eggleston DB (2016) The curious acoustic behavior of estuarine snapping shrimp: temporal patterns of snapping shrimp sound in sub-tidal oyster reef habitat. PLOS ONE 11:e0143691

*Boon PY, Yeo DCJ, Todd PA (2009) Sound production and reception in mangrove crabs Perisesarma spp. (Brachyura: Sesarmidae). Aquat Biol 5:107-116

* Brendonck L, Rogers DC, Olesen J, Weeks S, Hoeh WR (2008) Global diversity of large branchiopods (Crustacea: Branchiopoda) in freshwater. Hydrobiologia 595:167-176

*Buscaino G, Filiciotto F, Gristina M, Bellante A and others (2011a) Acoustic behaviour of the European spiny lobster Palinurus elephas. Mar Ecol Prog Ser 441:177-184

Buscaino G, Filiciotto F, Gristina M, Buffa G and others (2011b) Defensive strategies of European spiny lobster Palinurus elephas during predator attack. Mar Ecol Prog Ser 423:143-154

* Buscaino G, Filiciotto F, Buffa G, Di Stefano V and others (2012) The underwater acoustic activities of the red swamp crayfish Procambarus clarkii. J Acoust Soc Am 132: 1792-1798

Buscaino G, Gavio A, Galvan D, Filiciotto F and others (2015a) Acoustic signals and behaviour of Ovalipes trimaculatus in the context of reproduction. Aquat Biol 24: 61-73

* Buscaino G, Buffa G, Filiciotto F, Maccarrone V and others (2015b) Pulsed signal properties of free-ranging bottlenose dolphins (Tursiops truncatus) in the central Mediterranean Sea. Mar Mamm Sci 31:891-901

* Buscaino G, Ceraulo M, Pieretti N, Corrias V and others (2016) Temporal patterns in the soundscape of the shallow waters of a Mediterranean marine protected area. Sci Rep 6:34230

Caruso F, Alonge G, Bellia G, De Domenico E and others (2017) Long-term monitoring of dolphin biosonar activity in deep pelagic waters of the Mediterranean Sea. Sci Rep 7:4321

Ceraulo M, Papale E, Caruso F, Filiciotto F and others (2018) Acoustic comparison of a patchy Mediterranean shallow water seascape: Posidonia oceanica meadow and sandy bottom habitats. Ecol Indic 85:1030-1043

Ceraulo M, Moyano MPS, Bazterrica MC, Hidalgo FJ and others (2020) Spatial and temporal variability of the soundscape in a Southwestern Atlantic coastal lagoon. Hydrobiologia 847:2255-2277

* Coquereau L, Grall J, Chauvaud L, Gervaise C, Clavier J, Jolivet A, Di Iorio L (2016) Sound production and associated behaviours of benthic invertebrates from a coastal habitat in the north-east Atlantic. Mar Biol 163:127

Desjonquères C, Rybak F, Depraetere M, Gasc A, Le Viol I, Pavoine S, Sueur J (2015) First description of underwater acoustic diversity in three temperate ponds. PeerJ 3:e1393

* Diersch R, Melzer RR, Smola U (1999) Morphology of the compound eyes of two ancestral phyllopods, Triops cancriformis and Lepidurus apus (Notostraca: Triopsidae). J Crustac Biol 19:313-323

Favaro L, Tirelli T, Gamba M, Pessani D (2011) Sound production in the red swamp crayfish Procambarus clarkii (Decapoda: Cambaridae). Zool Anz 250:143-150

Filiciotto F, Sal Moyano MP, Hidalgo F, de Vincenzi G (2019) Underwater acoustic communication during the mating behaviour of the semi-terrestrial crab Neohelice granulata. Sci Nat 106:35 
Ferrara CR, Vogt RC, Giles JC, Kuchling G (2014) Chelonian vocal communication. In: Witzany G (ed) Biocommunication of animals. Springer, Dordrecht, p 261-274

Fry LL, Mulla MS, Adams CW (1994) Field introductions and establishment of the tadpole shrimp, Triops longicaudatus (Notostraca: Triopsidae), a biological control agent of mosquitos. Biol Control 4:113-124

Fryer G (1988) Studies on the functional morphology and biology of the Notostraca (Crustacea: Branchiopoda). Philos Trans R Soc B 321:27-124

Gueriau P, Rabet N, Clément G, Lagebro L and others (2016) A 365-million-year-old freshwater community reveals morphological and ecological stasis in branchiopod crustaceans. Curr Biol 26:383-390

Halliday TR, Slater PJB (eds) (1983) Animal behaviour, Vol 2: communication. Blackwell Scientific Publications, Oxford

Haver SM, Klinck H, Nieukirk SL, Matsumoto H, Dziak RP, Miksis-Olds JL (2017) The not-so-silent world: measuring Arctic, equatorial, and Antarctic soundscapes in the Atlantic Ocean. Deep-Sea Res A Oceanogr Res Pap 122: 95-104

Herzing DL (2015) Synchronous and rhythmic vocalizations and correlated underwater behavior of free-ranging Atlantic spotted dolphins (Stenella frontalis) and bottlenose dolphins (Tursiops truncatus) in the Bahamas. Anim Behav Cogn 2:14-29

Incagnone G, Marrone F, Barone R, Robba L, Naselli-Flores L (2015) How do freshwater organisms cross the 'dry ocean'? A review on passive dispersal and colonization processes with a special focus on temporary ponds. Hydrobiologia 750:103-123

Janik VM, Slater PJB (1998) Context-specific use suggests that bottlenose dolphin signature whistles are cohesion calls. Anim Behav 56:829-838

Jeffs A, Tolimieri N, Montgomery JC (2003) Crabs on cue for the coast: the use of underwater sound for orientation by pelagic crab stages. Mar Freshw Res 54:841-845

Jeppesen E, Christoffersen K, Landkildehus F, Lauridsen T, Amsinck SL, Riget F, Søndergaard M (2001) Fish and crustaceans in northeast Greenland lakes with special emphasis on interactions between Arctic charr (Salvelinus alpinus), Lepidurus arcticus and benthic chydorids. Hydrobiologia 442:329-337

Kaiser JF (1990) On a simple algorithm to calculate the energy of a signal. Proc IEEE Int Conf Acoust 2:381-384

Kaplan MB, Lammers MO, Zang E, Mooney TA (2018) Acoustic and biological trends on coral reefs off Maui, Hawaii. Coral Reefs 37:121-133

Koblick D (2021) Vectorized solar azimuth and elevation estimation. www.mathworks.com/matlabcentral/file exchange/23051-vectorized-solar-azimuth-and-elevationestimation

Korn M, Rabet N, Ghate HV, Marrone F, Hundsdoerfer AK (2013) Molecular phylogeny of the Notostraca. Mol Phylogenet Evol 69:1159-1171

Kuller Z, Gasith A (1996) Comparison of the hatching process of the tadpole shrimps Triops cancriformis and Lepidurus apus lubbocki (Notostraca) and its relation to their distribution in rain-pools in Israel. Hydrobiologia 335: $147-157$

Ladich F (1997) Agonistic behaviour and significance of sounds in vocalizing fish. Mar Freshwat Behav Physiol 29:87-108

Longhurst AR (1955) A review of the Notostraca. Bedford
College, London

* Lugli M, Pavan G, Torricelli P, Bobbio L (1995) Spawning vocalizations in male freshwater gobiids (Pisces, Gobiidae). Environ Biol Fishes 43:219-231

Marrone F, Alfonso G, Stoch F, Pieri V, Alonso M, Dretakis M, Naselli-Flores L (2019) An account on the non-malacostracan crustacean fauna from the inland waters of Crete, Greece, with the synonymization of Arctodiaptomus piliger Brehm, 1955 with Arctodiaptomus alpinus (Imhof, 1885) (Copepoda: Calanoida). Limnetica 38: $167-187$

* Mathers TC, Hammond RL, Jenner RA, Hänfling B, Gómez A (2013) Multiple global radiations in tadpole shrimps challenge the concept of 'living fossils'. PeerJ 1:e62

Montgomery JC, Jeffs A, Simpson SD, Meekan M, Tindle C (2006) Sound as an orientation cue for the pelagic larvae of reef fishes and decapod crustaceans. Adv Mar Biol 51: 143-196

Norris KS, Evans EC III (1988) On the evolution of acoustic communication systems in vertebrates. In: Nachtigall PE, Moore PWB (eds) Animal sonar: processes and performance. Springer, Boston, MA, p 655-669

Papale E, Prakash S, Singh S, Batibasaga A, Buscaino G, Piovano S (2020) Soundscape of green turtle foraging habitats in Fiji, South Pacific. PLOS ONE 15:e0236628

* Pasquali V (2015) Locomotor activity rhythms in high Arctic freshwater crustacean: Lepidurus arcticus (Branchiopoda; Notostraca). Biol Rhythm Res 46:453-458

* Pasquali V, D'Alessandro G, Gualtieri R, Leccese F (2017) A new data logger based on Raspberry-Pi for Arctic Notostraca locomotion investigations. Measurement 110: 249-256

*Pasquali V, Calizza E, Setini A, Hazlerigg D, Christoffersen KS (2019) Preliminary observations on the effect of light and temperature on the hatching success and rate of Lepidurus arcticus eggs. Ethol Ecol Evol 31:348-357

Pérez-Bilbao A, Benetti CJ, Garrido J (2015) Biodiversity and conservation of temporary ponds-assessment of the conservation status of 'Veiga de Ponteliñares', NW Spain (Natura 2000 Network), using freshwater invertebrates. In: Lo YH, Blanco JA, Roy S (eds) Biodiversity in ecosystems-linking structure and function. InTech, Rijeka, p 241-270

* Popper AN, Salmon M, Horch KW (2001) Acoustic detection and communication by decapod crustaceans. J Comp Physiol A 187:83-89

* Radford C, Jeffs A, Tindle C, Montgomery JC (2008) Resonating sea urchin skeletons create coastal choruses. Mar Ecol Prog Ser 362:37-43

Kosenthal GG, Ryan MJ (2000) Visual and acoustic communication in non-human animals: a comparison. J Biosci 25:285-290

Ruffo S (2005) Checklist e distribuzione della fauna italiana: 10.000 specie terrestri e delle acque interne. Memoire del Museo Civico di Storia Naturale di Verona, Verona

Sal Moyano MP, Ceraulo M, Mazzola S, Buscaino G, Gavio MA (2019) Sound production mechanism in the semiterrestrial crab Neohelice granulata (Brachyura, Varunidae). J Acoust Soc Am 146:3466-3474

* Salgado Costa C, Chuliver Pereyra M, Alcalde L, Herrera R, Trudeau VL, Natale GS (2014) Underwater sound emission as part of an antipredator mechanism in Ceratophrys cranwelli tadpoles. Acta Zool 95:367-374

* Sandeman DC, Wilkens LA (1982) Sound production by abdominal stridulation in the Australian Murray River 
crayfish, Euastacus armatus. J Exp Biol 99:469-472

Sassaman C (1991) Sex ratio variation in female-biased populations of Notostracans. Hydrobiologia 212:169-179

Simões JM, Duarte IG, Fonseca PJ, Turner GF, Amorim MC (2008) Courtship and agonistic sounds by the cichlid fish Pseudotropheus zebra. J Acoust Soc Am 124:1332-1338

Staaterman E, Claverie T, Patek SN (2010) Disentangling defense: the function of spiny lobster sounds. Bahaviour 147:235-258

Stella E, Margaritora FG, Cottarelli V (1972) La fauna ad entomostraci di acque astatiche della Sardegna nord orientale. Ricerche biologiche ed ecologiche. Rend Accad Naz XL 4:3-50

Takahashi F (1994) Use of the tadpole shrimp (Triops spp.) as a biological agent to control paddy weeds in Japan. In: Integrated management of paddy and aquatic weeds in Asia. Proceedings of an international seminar, Tsukuba, Japan, 19-25 October 1992. National Agriculture Research Center, Tsukuba, p 128-138

Thiéry A (1991) Multispecies coexistence of branchiopods (Anostraca, Notostraca \& Spinicaudata) in temporary ponds of Chaouia plain (western Morocco): sympatry or syntopy between usually allopatric species. Hydrobiologia 212:117-136

Tindall KV, Fothergill K (2012) Review of a new pest of rice, tadpole shrimp (Notostraca: Triopsidae), in the Midsouthern United States and a winter scouting method of rice fields for preplanting detection. J Integr Pest Manag 3:B1-B5

Tolimieri N, Jeffs AG, Montgomery JC (2000) Ambient sound as a cue for navigation by the pelagic larvae of reef

Editorial responsibility: Victor Benno Meyer-Rochow, Oulu, Finland

Reviewed by: 2 anonymous referees fishes. Mar Ecol Prog Ser 207:219-224

Troia A, Adragna F, Campisi P, Campo G and others (2016) I pantani di Anguillara (Calatafimi Segesta, Trapani): dati preliminari sulla biodiversità a supporto della tutela del biotopo. Nat Sicil 40:171-200

*van Oosterom L, Montgomery JC, Jeffs AG, Radford CA (2016) Evidence for contact calls in fish: conspecific vocalisations and ambient soundscape influence group cohesion in a nocturnal species. Sci Rep 6:19098

*Velonà A, Luchetti A, Scanabissi F, Mantovani B (2009) Genetic variability and reproductive modalities in European populations of Triops cancriformis (Crustacea, Branchiopoda, Notostraca). Ital J Zool 76:366-375

Versluis M (2000) How snapping shrimp snap: through cavitating bubbles. Science 289:2114-2117

*Waterkeyn A, Grillas P, Brendonck L (2016) Experimental test of the ecosystem impacts of the keystone predator Triops cancriformis (Branchiopoda: Notostraca) in temporary ponds. Freshw Biol 61:1392-1404

Williams DD (1997) Temporary ponds and their invertebrate communities. Aquat Conserv 7:105-117

* Williams WD, Busby JR (1991) The geographical distribution of Triops australiensis (Crustacea: Notostraca) in Australia: a biogeoclimatic analysis. Hydrobiologia 212: $235-240$

Zaffagnini F, Trentini M (1980) The distribution and reproduction of Triops cancriformis (Bosc) in Europe (Crustacea Notostraca). Ital J Zool 14:1-8

Zierold T, Hanfling B, Gómez A (2007) Recent evolution of alternative reproductive modes in the 'living fossil' Triops cancriformis. BMC Evol Biol 7:161

Submitted: October 30, 2020

Accepted: April 6, 2021

Proofs received from author(s): July 12, 2021 